\section{DOPAMINA E COMPORTAMENTO ALIMENTAR: POLIMORFISMOS EM RECEPTORES DOPAMINÉRGICOS E FENÓTIPOS RELACIONADOS À OBESIDADE}

\author{
DOPAMINE AND EATING BEHAVIOR: DOPAMINERGIC \\ RECEPTOR POLYMORPHISMS AND OBESITY- \\ RELATED PHENOTYPES
}

\author{
Gabriela Kaufmann"1, Fabiane Dresch², Stephanie Cristine Hepp \\ Rehfeldt², Júlia Pasqualini Genro', Verônica Contini²
}

\begin{abstract}
RESUMO
Dentre os sistemas neurais responsáveis pela ingestão dos alimentos, destacase a via dopaminérgica mesolímbica que, através da liberação de dopamina nos núcleos de accumbens, desperta prazer e motivação para recompensas químicas e naturais. Esta via de recompensa age através dos receptores dopaminérgicos transmembranares, que variam de DRD1 a DRD5. Desta forma, considerando os efeitos prazerosos despertados pela ingestão alimentar, é plausível que variações genéticas em genes do sistema dopaminérgico possam ter um papel na arquitetura genética da obesidade. Este estudo tem como objetivo realizar uma revisão narrativa da literatura sobre a influência de variantes genéticas nos receptores dopaminérgicos em fenótipos relacionados com a obesidade. Em conjunto, os principais achados desta revisão indicaram que os genes codificadores dos receptores DRD2 e DRD4 possam ser os mais relevantes no contexto da obesidade e fenótipos relacionados. No entanto, a obesidade é uma doença complexa e multifatorial e novos estudos são ainda necessários para uma melhor compreensão do impacto da dopamina nos desfechos relacionado à obesidade. É importante também destacar que esses efeitos podem ser específicos para subgrupos de pacientes e que outros fatores, além das variantes genéticas, devem ser considerados.
\end{abstract}

Palavras-chave: Obesidade; Polimorfismo; Comportamento alimentar; Receptores dopaminérgicos

\begin{abstract}
Among the neural systems responsible for food ingestion, the mesolimbic dopaminergic pathway stands out by eliciting pleasure and motivation for chemical and natural rewards through the release of dopamine in the nucleus accumbens. This reward pathway is regulated by transmembrane dopaminergic receptors, which range from DRD1 to DRD5. Thus, considering the pleasurable effects aroused by food intake, it is plausible that genetic variations in genes of the dopaminergic system may have a role in the genetic architecture of obesity. This study aims to conduct a narrative review of the literature on the influence of genetic variants of dopaminergic receptors on obesity-related phenotypes. Taken together, the main findings of this review indicated that the genes encoding the DRD2 and DRD4 receptors may be the most relevant in the context of obesity and related phenotypes. However, obesity is a complex and multifactorial disease and new studies are still being conducted to better understand the impact of dopamine on obesity-related outcomes. It is also important to note that these effects can be specific to subgroups of patients and that other factors, in addition to genetic variants, must be considered.
\end{abstract}

Keywords: Obesity; Polymorphism; Feeding behavior; Dopaminergic receptors
Clin Biomed Res. 2021;41(3):245-253

1 Programa de Pós-Graduação em Biociências, Universidade Federal de Ciências da Saúde de Porto Alegre. Porto Alegre, RS, Brasil.

2 Programa de Pós-Graduação em Biotecnologia, Universidade do Vale do Taquari (Univates). Lajeado, RS, Brasil.

Autor correspondente:

Verônica Contini

veronica.contini@univates.br

Universidade do Vale do

Taquari (Univates)

Rua Avelino Talini, 171

95914-014, Lajeado, RS, Brasil. 


\section{INTRODUÇÃO}

A prevalência da obesidade vem aumentando ao longo dos últimos anos e estimativas apontam que, até $2030,38 \%$ da população adulta do mundo esteja acima do peso e outros $20 \%$ sejam obesos, o que resulta em um grande impacto socioeconômico, visto que esta patologia é considerada um potente fator para o desenvolvimento de várias doenças, principalmente doenças cardiovasculares, diabetes e câncer ${ }^{1}$.

Do ponto de vista etiológico, a obesidade é caracterizada como uma doença multifatorial e, clinicamente, é definida como um valor de índice de massa corporal (IMC) acima de $30 \mathrm{~kg} / \mathrm{m}^{2}$. Esta condição é impulsionada por um aumento exagerado do consumo de alimentos hipercalóricos, combinado com hábitos sedentários, o que acarreta um desequilíbrio energético, desencadeando um acúmulo exagerado de lipídeos no interior de adipócitos².

Devido a sua etiologia complexa, tem sido observada uma variabilidade significativa na susceptibilidade à obesidade entre os indivíduos expostos aos mesmos fatores ambientais. Esta observação sugere que as diferenças genéticas possuem um papel significativo na variação individual observada no peso corporal e, desta forma, as primeiras estratégias para investigar o papel da genética na obesidade consistiram em estudos genéticos clássicos, com famílias, gêmeos e adotados. Os estudos com gêmeos estimam que a herdabilidade deste fenótipo varie entre $40 \%$ e $70 \%{ }^{3}$. Posteriormente, diversas abordagens foram utilizadas objetivando a identificação dos genes envolvidos, dentre elas, estudos de genes candidatos, estudos de ligação e estudos de varredura genômica (GWAS).

Diversas varreduras genômicas já identificaram mais de 300 loci relacionados com a obesidade. Além disso, concluíram que determinados polimorfismos em genes expressos no hipotálamo possuem relação direta com a regulação da massa corporal, o que não é surpreendente, uma vez que a ingestão de alimentos e o gasto energético são fortemente controlados pelo sistema nervoso central $(\mathrm{SNC})^{4-6}$.

Os modelos que explicam o controle do SNC sobre a ingestão alimentar propõem dois mecanismos: a) mecanismos homeostáticos e b) mecanismos hedônicos. O sistema homeostático consiste na regulação da homeostasia energética por meio de uma complexa interação entre reguladores hormonais periféricos, como a leptina, grelina e insulina, por exemplo, e neuropeptídios anorexígenos ${ }^{7}$. Esse sistema atua, principalmente, no núcleo arqueado, estimulando ou inibindo o apetite, de forma a manter um balanço energético adequado e assegurando que a quantidade consumida em uma única refeição não exceda o que o corpo pode suportar com segurança ${ }^{8}$. Por outro lado, o sistema hedônico pode ser entendido como um sistema de recompensa cerebral que medeia as recompensas naturais e não naturais. Consiste em mecanismos moleculares e celulares envolvendo diversos mensageiros químicos como a serotonina, o ácido $y$-aminobutírico, o glutamato, a acetilcolina, entre outros, que atuam em conjunto para estimular a liberação de dopamina (DA) no núcleo accumbens (NAc) e, consequentemente, desencadear uma sensação de prazer ${ }^{9,10}$.

Por meio de ligação da DA com seus respectivos receptores, os impulsos naturais - como a alimentação e a reprodução - ou não naturais - como drogas, jogos de azar ou comportamentos de risco - são responsáveis por desencadearem uma forte resposta hedônica (sensação de satisfação e prazer) que, em certos indivíduos, pode sobrepor os estímulos homeostáticos e desencadear fenótipos psicossomáticos característicos, como a obesidade ${ }^{11}$. Sendo assim, esta relação da DA com a saciedade, mediada pelo prazer, pode ter um papel importante na arquitetura genética da obesidade e, consequentemente, no comportamento alimentar e na suscetibilidade individual ao ganho de peso. Desta forma, diante do contexto exposto acima, o objetivo do presente trabalho é revisar os achados da literatura sobre a influência de variantes genéticas nos receptores dopaminérgicos em fenótipos relacionados com a obesidade.

\section{DOPAMINA E O SISTEMA DE RECOMPENSA}

ADAé a catecolamina predominante no cérebro e é sintetizada por neurônios mesencefálicos na substância nigra (SN) e na área tegmental ventral. A principal via dopaminérgica, chamada de mesolímbica, impulsiona comportamentos gratificantes, como a alimentação, ao ativarem o sistema de recompensa cerebral. A cascata da recompensa cerebral, desencadeada pela alimentação, depende da efetiva interrelação da via dopaminérgica com as vias serotoninérgica, endorfinérgica e GABAérgica ${ }^{12,13}$.

O SNC dispõe de mecanismos intrínsecos que mantêm esse sistema equilibrado, evitando que o sistema de recompensa se sobreponha aos sinais homeostáticos e, assim, promova o aumento de peso ${ }^{14}$. Geralmente drogas, como o álcool, os psicoestimulantes, e opiáceos, e comportamentos de risco, como comer excessivamente ou a prática constante de jogos de azar, desencadeiam uma liberação de DA na região mesolímbica e, por meio de comportamentos compensatórios, suprem a hipofunção dopaminérgica, levando a uma rápida sensação de bem-estar e tornando-se potentes reforçadores de prazer ${ }^{15,16}$.

A recompensa alimentar pode ser dividida em 3 componentes principais: a) motivação de incentivo (wanting), a qual refere-se a processos que facilitam a antecipação de recompensa ou de aproximação 
a comportamentos em direção às metas biologicamente relevantes, incluindo avaliação de recompensa, vontade realizar esforços para obter recompensas, previsão de recompensa e recompensa baseada em tomada de decisão; b) componente hedônica (liking), que, nesse caso, é o próprio comportamento alimentar e todos os processos relacionados e; c) aprendizagem (learning), que permite fazer associações e predições a partir de experiências prévias e orientar comportamentos futuros. É importante notar que esses fenômenos podem ser aplicados tanto a recompensas naturais, como alimentos, quanto a reforços artificiais, como drogas. Nesse sentido, verificou-se que indivíduos com excesso de peso têm um aumento do wanting e da ingestão energética na ausência de fome e, também, uma diminuição do liking após as refeições. Isso sugere que indivíduos obesos possuem uma dificuldade na obtenção de recompensa, o que os leva a uma procura excessiva pela recompensa alimentar ${ }^{17,18}$.

Estudos de neuroimagem sugerem que indivíduos obesos apresentam uma disponibilidade de receptores da DA inferior à de indivíduos eutróficos, bem como uma menor ativação da DA na região estriada, em resposta à ingestão de alimentos de elevada palatibilidade ${ }^{19,20}$. Um estudo, realizado a partir de imagens obtidas por tomografiapor emissão de pósitrons (PET), demonstrou que indivíduos obesos possuem alterações nos receptores dopaminérgicos que levam à hiperfagia e, consequentemente, à obesidade ${ }^{21}$. Já um estudo com imagens obtidas por ressonância funcional magnética demonstrou que indivíduos obesos apresentam maior ativação dopaminérgica em resposta a imagens de alimentos, comparativamente a controles eutróficos ${ }^{22}$. Estes dados sugerem que na obesidade há uma dificuldade na obtenção da recompensa, através da ingestão, e uma maior sensibilidade aos estímulos de alimentos. De fato, outro estudo, que avaliou mulheres que aumentaram de peso em um período de seis meses, demonstrou uma redução na resposta dopaminérgica, em resposta à ingestão de alimentos de elevada palatibilidade, nessas mulheres, em comparação com mulheres com um peso mais estável ${ }^{23}$.

Existem ainda evidências de que a ingestão de alimentos de elevada palatibilidade leva a uma atenuação na sinalização da DA. Em animais, como ratos e primatas, a ingestão frequente de alimentos ricos em açúcar e em gordura parece levar a uma diminuição de receptores dopaminérgicos póssinápticos, e diminuição da sua sensibilidade bem como da sensibilidade à recompensa, além de promover neuroplasticidade, alterações epigenéticas, perturbações no desenvolvimento do metabolismo dopaminérgico estriatal e maior dificuldade em controlar a ingestão de alimentos energeticamente densos, além de outras mudanças no padrão de interação social intraespecífica ${ }^{24,25}$.
Entretanto, os indivíduos apresentam uma ampla variação em relação a comportamentos compulsivos, ansiosos ou aditivos. Nesse sentido, visto que os mecanismos envolvendo a sinalização dopaminérgica são mediados pelos receptores de dopamina e, estes, codificados por genes específicos, polimorfismos nestes genes podem perturbar os eventos neuroquímicos de sinalização neuronal da DA. A partir disso, Blum et al. ${ }^{26}$ propuseram que alguns indivíduos apresentam características genéticas específicas que predispõem a uma hipofunção dopaminérgica na região mesolímbica e caracterizaram esse fenômeno como síndrome de deficiência de recompensa (RDS).

A RDS refere-se a uma insuficiência de sentimentos habituais de satisfação, causados por uma disfunção na cascata de recompensa cerebral, envolvendo principalmente neurotransmissores dopaminérgicos e opióides. Blum et al. ${ }^{27}$ ligaram esta disfunção a um padrão genético específico e, a partir de um estudo desenvolvido com 55 indivíduos de duas famílias distintas, em 2011, sugeriu-se que polimorfismos em genes que codificam receptores dopaminérgicos desempenham um papel fundamental no desenvolvimento da RDS. Ou seja, a RDS pode ser entendida como o ponto de ligação entre o comportamento impulsivo de busca pela recompensa e as características genéticas e epigenéticas responsáveis pelas alterações no sistema dopaminérgico.

\section{RECEPTORES DOPAMINÉRGICOS}

Amplamente distribuídos pelo SNC, os receptores de DA (DARs) pertencem ao grupo de receptores acoplados à proteína $\mathrm{G}$. Em mamíferos, existem cinco subtipos de DARs, divididos em duas famílias de acordo com a sua estrutura e resposta biológica. $\mathrm{Na}$ família de receptores D1-like incluem-se os DARs D1 e D5, enquanto os DARs da família D2like consistem no D2, D3 e D4 28,29 .

Os DARs D1-like são acoplados positivamente a adenil-ciclase e induzem a acumulação de monofosfato de adenosina cíclica (AMPc) intracelular e a ativação da proteínaquinase $A(P K A)$. Esta família de receptores é amplamente expressa no cérebro, sendo que a maior parte se encontra no núcleo estriado, putâmen, NAc e SN. Além disso, desempenham um papel importante na atividade motora, sistemas de recompensa, aprendizado e memória ${ }^{30}$.

Por outro lado, os DARs D2-like estão negativamente acoplados à adenil-ciclase e, como resultado, reduzem a acumulação de $A M P c$ intracelular e, consequentemente, de PKA. Ou seja, a ativação desta família de receptores leva tanto à inibição da atividade da adenil-ciclase como, também, à inibição da PKA. Esses receptores são principalmente expressos na região estriada, pallidum, NAc, amígdala, 
córtex cerebral, hipocampo e na glândula pituitária e desempenham um papel importante na RDS e, portanto, no comportamento alimentar ${ }^{28,31}$.

\section{GENE DRD1}

O receptor de DA tipo D1 (DRD1) é codificado pelo gene DRD1, expresso principalmente no núcleo caudado, NAc e tubérculo olfatório no SNC. Localizado no cromossomo 5, o gene possui pouco mais de 4000 pares de base (pb) e produz apenas um transcrito, a partir de dois éxons. O produto obtido por meio da transcrição possui 446 resíduos de aminoácidos, pesando aproximadamente $49293 \mathrm{kDa}^{32}$.

Apesar dos diversos polimorfismos já descritos no gene, dois polimorfismos de base única (SNP) (rs4532 e rs686) têm sido mais extensivamente investigados, sendo descritas associações com fenótipos de adição, como a dependência de álcool, nicotina e opioides ${ }^{33}$, com fenótipos psiquiátricos, como a esquizofrenia ${ }^{34}$, e com pior resposta ao tratamento farmacológico com antipsicóticos ${ }^{35}$. O rs4532 está localizado a -48 pb na região 5' não traduzida (UTR) do segundo éxon e refere-se a uma troca de adenina $(A)$ por guanina $(G)^{36}$. Já o rs686 descreve uma troca de A por G na região 3' UTR, que desencadeia uma interferência na expressão do gene. Com relação ao rs686, Huang e Li demonstraram que a presença do alelo $\mathrm{G}$ diminui a expressão do gene, devido a interferência de um microRNA (miRNA). Ainda, uma vez que o miR-504 está localizado no cromossomo $\mathrm{X}$, os autores sugerem que esse miRNA possa influenciar de maneira distinta o comportamento impulsivo entre os sexos ${ }^{37}$. De fato, alguns estudos têm demonstrado que a presença dos alelos de risco dos polimorfismos rs4532 e rs686 pode levar os indivíduos a adotarem comportamentos impulsivos e à RDS, sendo que a presença do haplótipo de risco G-G implica em manifestações mais exacerbadas ${ }^{38}$.

Apenas um estudo investigou a associação do polimorfismo rs4532 com a obesidade, em uma amostra de 245 indivíduos norte-americanos, destes $111 \mathrm{com} I M C \geq 30 \mathrm{~kg} / \mathrm{cm}^{2}$. Os resultados, no entanto, não evidenciaram efeitos significativos do polimorfismo ${ }^{36}$. Apesar deste achado negativo, alguns autores sugerem uma associação entre o gene codificador deste receptor com a motivação para realização de exercícios físicos, tanto em modelos animais quanto humanos, sugerindo um possível efeito no comportamento sedentário ${ }^{39}$.

\section{GENES DRD2 E ANKK1}

O receptor D2 é codificado pelo gene de mesmo nome, DRD2, Localizado no cromossomo 11. É constituído por mais de 6000 pb e pode produzir dez transcritos diferentes. Embora algumas fontes mencionem a existência de três isoformas ${ }^{31}$, os receptores D2 são amplamente expressos no cérebro humano sob duas principais isoformas: D2 longo (D2L), em terminais pós-sinápticos, e D2 curto (D2S), em terminais pré-sinápticos. As duas isoformas, D2L e D2S, são resultado de um splicing alternativo no éxon 6 do gene, sendo que o D2L difere do D2S pela presença de 29 aminoácidos adicionais no interior do terceiro loop intracelular. Ao final do processo de transcrição do D2L, os sete éxons codificantes originam uma proteína com 443 resíduos de aminoácidos e, portanto, esta foi classificada como a sequência canônica. Este splicing alternativo resulta em diferenças na afinidade dos receptores com a proteína $\mathrm{G} 37^{40}$.

O gene DRD2 apresenta uma variedade de SNPs, e o polimorfismo mais investigado, e associado a comportamentos patológicos, é rs1800497, localizado na região 3'UTR. No entanto, embora este polimorfismo esteve originalmente associado ao gene DRD2, verificou-se posteriormente que ele se localiza no éxon 8 do gene ankyrin repeat and kinase domain containing 1 (ANKK1), adjacente ao gene DRD2 ${ }^{41}$. Os alelos deste polimorfismo são designados por A2 (citosina) e A1 (timina), sendo que a substituição da citosina $(C)$ pela timina $(T)$, na região $32806 \mathrm{pb}$, resulta na troca de um glutamato por uma lisina $(713 \mathrm{G} / \mathrm{u} / \mathrm{Lys})$, o que afeta a especificidade da ligação da proteína ao substrato. Diversos estudos genéticos já associaram o polimorfismo rs 1800497 com fenótipos de adição em opióides, antidepressivos, estimulantes, alucinógenos e outras substâncias, como álcool e tabaco ${ }^{41}$.

Noble et al., em 1994, relataram a primeira associação entre o alelo A1 do polimorfismo rs1800497 com a obesidade, e com a preferência por carboidratos, em uma amostra de 73 indivíduos obesos ${ }^{42}$. Ainda, outro estudo realizado por Obregón et al. ${ }^{43}$, com 258 crianças, revelou que a presença do alelo $A 1$ estava relacionado com o desenvolvimento de um comportamento alimentar compulsivo, associado à ingestão de alimentos calóricos e ao comer hedônico. Estes estudos, portanto, sugerem que as variações genéticas que estão associadas a sinalização de DA podem influenciar a ingestão de alimentos ricos em gordura saturada e, desta forma, a obesidade. Corroborando essa hipótese, outro estudo, realizado com 394 adultos, também relacionou o polimorfismo rs1800497 com a preferência, ingestão e desejo por alimentos palatáveis ${ }^{44}$.

Em relação ao gene DRD2 propriamente dito, o rs6277 vem sendo constantemente associado a comportamentos compulsivos ${ }^{45}$, uma vez que o alelo de risco C está associado a menor disponibilidade de receptores DRD2 tanto nas regiões estriadas quando nas extra-estriatais e em distúrbios psiquiátricos ${ }^{46}$. 
Partindo desse pressuposto, Davis et al. detectaram uma associação deste polimorfismo com comportamento alimentar anormal, caracterizado pelo aumento da ingestão de alimentos palatáveis, em um estudo com 230 indivíduos obesos com transtorno de compulsão alimentar ${ }^{47}$. Mais recentemente, Kvaløy et al. ${ }^{48}$ identificaram efeitos semelhantes em um grande estudo longitudinal, envolvendo 3999 participantes que compunham a amostra do estudo HUNT2, realizado entre 1995 e 1997 e/ou HUNT3, desenvolvido de 2006 a 2008. A partir dos dados obtidos pela coorte HUNT, realizada na Noruega, os autores identificaram uma associação entre a presença do alelo de risco T do rs6277 e um aumento de peso ao longo dos anos nos indivíduos pesquisados.

A fim de confirmar a importância do receptor DRD2 na obesidade, Dang et al.$^{49}$ selecionaram 130 indivíduos saudáveis, com idades entre 18 e 81 anos e, utilizando PET e radioisótopos com alta afinidade por receptores D2/D3, demonstraram uma correlação inversa entre a disponibilidade destes receptores, principalmente no mesencéfalo e nas regiões estriadas ventral e dorsal (putâmen), e o IMC, em indivíduos com mais de 30 anos. Já em indivíduos com menos de 30 anos, a disponibilidade de receptores não foi significativamente associada ao IMC.

Blum et al..$^{50}$ desenvolveram e validaram um novo modelo animal para avaliar os efeitos do DRD2, utilizando a biotecnologia do sistema ioxp-CRE rescue. Dessa forma, ratos knockdown heterozigotos e homozigotos expressavam apenas $55 \%$ e $3 \%$, respectivamente, do mRNA total encontrado, desencadeando assim, o fenótipo de interesse: redução na quantidade de mRNA do gene DRD2 e não sua completa ausência. Como resultado, os autores demonstraram que, ao contrário do que ocorre na RDS, os animais aumentam de peso devido a inatividade física e não a uma alimentação com padrão compulsivo.

Diante destes achados, os autores sugerem que a influência do DRD2 no IMC não ocorre de forma casual e depende, em grande parte, da idade do indivíduo, o que poderia influenciar os achados de associação entre polimorfismos no gene DRD2 e a obesidade, evidenciando a complexidade do fenótipo.

\section{GENE DRD3}

O receptor D3 é produzido a partir do gene DRD3, localizado na posição $3 q 13.31$, sendo expresso quase que unicamente no NAc. O polimorfismo mais estudado no gene, o rs6280, é um SNP no qual uma adenina (A) é substituída por uma guanina (G), o que resulta em uma substituição de uma glicina por uma serina na posição 9 (ser9gly), na parte $\mathrm{N}$-terminal da parte extracelular do receptor. Com essa substituição, a proteína não é capaz de se inserir de forma correta na membrana e, assim, indivíduos heterozigotos para o alelo gly possuem receptores com uma maior afinidade pela DA ${ }^{51,52}$.

Estudos relacionando o gene DRD3 a alterações no peso corporal encontram associação significativa, principalmente quando os pacientes sofrem de algum outro transtorno psiquiátrico e/ou estão em tratamento farmacológico. De fato, estudos de farmacogenética têm associado a presença do alelo de risco gly do rs6280 a um maior aumento de peso e a presença de distúrbios metabólicos induzidos por antipsicóticos ${ }^{52,53}$.

Contrastando com a vasta literatura acerca desse tema em fenótipos psiquiátricos, não há estudos associando o polimorfismo rs6280 no gene DRD3 a um aumento do IMC ou obesidade na população geral. Entretanto, o estudo de McQuade et al. ${ }^{54}$, com ratos knockout para o gene (DRD3 ${ }^{-1-}$ ), demonstrou que esses animais apresentaram um aumento de peso e de percentual de gordura corporal, e que tais alterações antropométricas modificaram também os níveis de insulina e leptina plasmáticas. Apesar do estudo envolver apenas animais e não haver dados que comprovem o efeito em seres humanos, Yazdi et al. ${ }^{55}$ sugerem que sejam realizados outros estudos em modelos animais, com metodologias mais refinadas, com o intuito de melhor compreender as funções e participação deste gene na obesidade.

\section{GENE DRD4}

O gene DRD4, localizado no cromossomo 11, codifica o receptor D4 de DA, o qual é altamente expresso no córtex pré-frontal e em outras regiões do cérebro envolvidas nos circuitos de recompensa, que medeiam as propriedades de reforço de alimentos, tais como o hipocampo, a amígdala e hipotálamo ${ }^{56}$. Esse gene codifica um receptor com sete domínios transmembranares, que responde à DA endógena e inibe o segundo mensageiro adenil-ciclase.

Um dos polimorfismos mais investigados no gene DRD4 está localizado no éxon 3, o qual se caracteriza pela presença de um número variável de repetições em tandem (VNTR), no qual uma sequência de $48 \mathrm{pb}$ (16 aminoácidos) pode estar repetida de duas à onze vezes, sendo que duas ( $2 R)$, quatro $(4 R)$ ou sete repetições $(7 R)$ representam os alelos mais comuns. Na literatura, os indivíduos podem ser ainda agrupados como portadores da variação short ou portadores da variação long, sendo que a categoria de short é definida como seis ou menos repetições e long com sete ou mais repetições ${ }^{57}$.

Estudos sugerem que indivíduos portadores de pelo menos um alelo $7 \mathrm{R}$ possuem menor quantidade e afinidade dos receptores dopaminérgicos e, consequentemente, transmitem sinais intracelulares mais fracos, em comparação com outros alelos. Além disso, esta variante tem sido associada a menor 
formação de $\mathrm{AMPc}$, em comparação com seis repetições ou menos ${ }^{58}$. Ainda, o alelo 7R tem sido associado a uma pior resposta a drogas estimulantes da DA, como álcool, cocaína, e outros estimulantes, e menor liberação de DA nas regiões do caudado e ventral do $\mathrm{NAc}^{59}$.

De maneira semelhante ao reforço obtido por meio de drogas, a alimentação gera grandes impulsos de reforço e alguns estudos já associaram polimorfismos no gene DRD4 com fenótipos relacionados à obesidade ${ }^{60}$. Além destes achados, Silveira et al. ${ }^{59}$ e Fontana et al. ${ }^{61}$ realizaram estudos com crianças e constataram que portadores do alelo $7 R$ possuem maior tendência ao consumo de alimentos palatáveis em relação à alimentos integrais.

\section{GENE DRD5}

Localizado na posição 4p16.1, o gene DRD5 é responsável pela síntese de um subtipo de receptores D1-like. Ao ser transcrito em regiões límbicas, o gene origina um mRNA formado por apenas um éxon, entretanto, devido à grande homologia estrutural $e$ funcional com o receptor D1, a proteína sintetizada a partir do gene DRD5 é preferencialmente denominada DRD1B, possuindo 477 resíduos de aminoácidos ${ }^{62}$.

O polimorfismo mais investigado no gene DRD5 é um VNTR que consiste na repetição de um dinucleotídeo (CT), localizado a $18,5 \mathrm{~kb}$ upstream do gene, o qual tem sido associado com a transcrição do gene ${ }^{62}$. Os possíveis alelos variam de duas a 13 repetições, sendo que o alelo de 9 repetições $(9 R)$, com $148 \mathrm{pb}$, parece aumentar o risco para o Transtorno de Déficit de Atenção/Hiperatividade (TDAH), ao passo que o alelo com $136 \mathrm{pb}$ parece conferir um efeito protetor ${ }^{63}$. Interessantemente, alguns autores defendem que exista uma ligação entre o TDAH e a obesidade e que o TDAH seja, na verdade, um subtipo da RDS, o que explicaria sintomas como impulsividade, por exemplo ${ }^{64}$.

No que diz respeito a fenótipos relacionados à obesidade, Carr et al ${ }^{36}$ avaliaram a possível associação entre o VNTR descrito acima, o reforço alimentar e alterações no IMC. Para tanto, investigaram a ausência ou presença do alelo 9R em 245 indivíduos, destes 111 obesos. No entanto, apesar do alelo 9R ser o mais comum na amostra investigada (41\%), não foram encontradas associações entre o polimorfismo e o comportamento alimentar e/ou IMC.

\section{DISCUSSÃO}

Nosso estudo revisou os principais artigos que avaliaram polimorfismos nos genes codificadores dos receptores de dopamina em fenótipos relacionados à obesidade. A dopamina desempenha um papel fundamental no equilíbrio energético ao integrar sinais metabólicos com circuitos que suportam funções cognitivas, perceptuais e apetitivas que orientam a alimentação. Ainda, foi estabelecido que a dieta e a obesidade alteram a sinalização de DA, levando à alimentação compulsiva e a comprometimentos neurocognitivo ${ }^{26}$.

Ressalta-se que a grande maioria das variantes genéticas investigadas são as mesmas já associadas com transtornos mentais, especialmente os relacionados a comportamentos aditivos e compulsivos, o que reforça a importância do SNC no controle do peso. No entanto, embora as substâncias psicoativas e os alimentos compartilhem a característica de exercerem um efeito de reforço, ao aumentar abruptamente a liberação de DA na região mesolímbica ${ }^{30}$, Cornelis et al. ${ }^{65}$ defendem que possam existir mecanismos distintos para o desenvolvimento da compulsão alimentar ou drogadição, que permanecem desconhecidos. Portanto, os loci envolvidos com o comportamento patológico alimentar podem ser diferentes dos loci envolvidos nos transtornos por uso de substâncias.

Os achados mais relevantes desta revisão estão relacionados com o receptor DRD2, porém, sabe-se que receptores DRD2 e DRD4 podem formar heterodímeros complexos, de acordo com a presença de determinadas variantes genéticas ${ }^{66}$, o que reforça a importância da investigação conjunta de polimorfismos nos genes DRD2 e DRD4. Além disso, a complexidade do fenótipo é também evidenciada pelo estudo de Dang et al. ${ }^{49}$, que demonstraram que a possível influência dos receptores de DA sobre o IMC pode depender, em grande parte, da idade do indivíduo, visto que, ao longo dos anos, a quantidade de receptores pode ser reduzida gradativamente, ao passo que há um aumento no IMC. Estudos como esse contradizem a hipótese de hipofunção dopaminérgica e sistema de recompensa e sugerem um novo mecanismo, onde as alterações metabólicas decorrentes da obesidade seriam responsáveis pela alteração na função dopaminérgica. Seguindo essa linha de raciocínio, Beeler et al. ${ }^{67}$ acrescenta que a obesidade associada com níveis reduzidos de receptores $\mathrm{D} 2$ poderia ser desencadeada pela redução da atividade física, e não por um padrão compulsivo de alimentação, conforme também defendido por Blum et al..$^{50}$. Por fim, outra questão que ainda deve ser destacada em relação à funcionalidade da sinalização dopaminérgica é a presença de polimorfismos em outros genes. Gluskin e Mickey, em uma meta-análise, identificaram 19 variantes em 11 genes distintos que poderiam exercer influência sobre a capacidade de ligação da DA com seu receptor DRD2, em estudos in vivo e que, devido a esse fenômeno, a disponibilidade de receptores DRD2 pode variar entre 20 e $60 \%$ dentre os indivíduos ${ }^{45}$. 


\section{CONCLUSÃO}

A obesidade é claramente uma doença complexa e multifatorial, portanto, é aceitável a existência de achados com resultados conflitantes. Apesar das evidências apresentadas, novos estudos são ainda necessários para uma melhor compreensão do impacto da DA nos desfechos relacionado à obesidade. Por fim, é importante também destacar que esses efeitos podem ser específicos para subgrupos de pacientes e que outros fatores, além das variantes genéticas, devem ser considerados.

\section{Agradecimentos}

Os autores agradecem à FUVATES, ao CNPq e à CAPES (código 001), pela concessão de bolsas de estudo.

\section{REFERÊNCIAS}

1. Kelly T, Yang W, Chen CS, Reynolds K, He J. Global burden of obesity in 2005 and projections to 2030. Int J Obes (Lond). 2008;32(9):1431-7.

2. Bays $\mathrm{H}$. Central obesity as a clinical marker of adiposopathy; increased visceral adiposity as a surrogate marker for global fat dysfunction. Curr Opin Endocrinol Diabetes Obes. 2014;21(5):345-51.

3. Bray MS, Loos RJ, McCaffery JM, Ling C, Franks PW,

Weinstock GM, et al. NIH working group report-using genomic information to guide weight management: From universal to precision treatment. Obesity (Silver Spring). 2016;24(1):14-22.

4. Shungin D, Winkler TW, CroteauChonka DC, Ferreira T, Locke AE, Mägi R, et al. New genetic loci link adipose and insulin biology to body fat distribution. Nature. 2015;518(7538):187-96.

5. Sun X, Luquet $S$, Small DM. DRD2: Bridging the Genome and Ingestive Behavior. Trends Cogn Sci. 2017;21(5):372-84.

6. Min J, Chiu DT, Wang Y. Variation in the heritability of body mass index based on diverse twin studies: a systematic review. Obes Rev. 2013;14(11):871-82.

7. Tabe-Bordbar S, Anastasio TJ. Computational Analysis of the Hypothalamic Control of Food Intake. Front Comput Neurosci. 2016;10:27.

8. Çakir I, Perello M, Lansari O, Messier NJ, Vaslet CA, Nillni EA. Hypothalamic Sirt1 regulates food intake in a rodent model system. PLoS One. 2009;4(12):e8322.

9. Frank $S$, Veit $R$, Sauer $H$, Enck $P$, Friederich $\mathrm{HC}$, Unholzer T, et al. Dopamine Depletion Reduces Food-
Related Reward Activity Independent of BMI. Neuropsychopharmacology. 2016;41(6):1551-9.

10. Westerink BH, Kwint HF, deVries JB. The pharmacology of mesolimbic dopamine neurons: a dual-probe microdialysis study in the ventral tegmental area and nucleus accumbens of the rat brain. J Neurosci. 1996;16(8):2605-11.

11. Schwartz MW, Woods SC, Porte D Jr, Seeley RJ, Baskin DG. Central nervous system control of food intake. Nature. 2000;404(6778):661-71.

12. Bello NT, Hajnal A. Dopamine and binge eating behaviors. Pharmacol Biochem Behav. 2010;97(1):25-33.

13. Kishi T, Elmquist JK. Body weight is regulated by the brain: a link between feeding and emotion. Mol Psychiatry. 2005;10(2):132-46.

14. Kim HF, Hikosaka O. Parallel basal ganglia circuits for voluntary and automatic behaviour to reach rewards. Brain. 2015;138(7):1776-800.

15. Leyton M, Vezina P. Dopamine ups and downs in vulnerability to addictions: A neurodevelopmental model. Trends Pharmacol Sci. 2014;35(6):268-76.

16. Covey DP, Roitman MF, Garris PA. Illicit dopamine transients: Reconciling actions of abused drugs. Trends Neurosci. 2014;37(4):200-10.

17. Ramachandrappa S, Farooqi IS. Genetic approaches to understanding human obesity. J Clin Invest. 2011;121(6):2080-6.

18. Blum K, Simpatico T, Badgaiyan $\mathrm{RD}$, Demetrovics Z, Fratantonio J, Agan G, et al. Coupling Neurogenetics (GARS ${ }^{\mathrm{TM}}$ ) and a Nutrigenomic Based Dopaminergic Agonist to Treat Reward Deficiency Syndrome (RDS): Targeting
Polymorphic Reward Genes for Carbohydrate Addiction Algorithms. J Reward Defic Syndr. 2015;1(2):75-80.

19. Frank GKW. Advances from neuroimaging studies in eating disorders. CNS Spectr. 2015;20(4):391-400.

20. Stice E, Figlewicz DP, Gosnell BA, Levine AS, Pratt WE. The contribution of brain reward circuits to the obesity epidemic. Neurosci Biobehav Rev. 2013;37(9):2047-58.

21. Guo J, Simmons WK, Herscovitch $P$, Martin A, Hall KD. Striatal dopamine D2-like receptor correlation patterns with human obesity and opportunistic eating behavior. Mol Psychiatry. 2014;19(10):1078-84.

22. Stice E, Spoor S, Bohon C, Veldhuizen MG, Small DM. Relation of reward from food intake and anticipated food intake to obesity: A functional magnetic resonance imaging study. J Abnorm Psychol. 2008;117(4):924-35.

23. Stice E, Yokum S, Blum K, Bohon C. Weight gain is associated with reduced striatal response to palatable food. J Neurosci. 2010;30(39):131059.

24. Vucetic Z, Carlin JL, Totoki K, Reyes TM. Epigenetic dysregulation of the dopamine system in dietinduced obesity. $J$ Neurochem. 2012;120(6):891-8.

25. Marco A, Schroeder M, Weller A. Feeding and reward: Ontogenetic changes in an animal model of obesity. Neuropharmacology. 2012;62(8):2447-54.

26. Blum K, Thanos PK, Gold MS. Dopamine and glucose, obesity and reward deficiency syndrome. Front Psychol. 2014;5:919.

27. Blum K, Chen AL, Oscar-Berman M Chen TJ, Lubar J, White N, et al. Generational association studies 
of dopaminergic genes in reward deficiency syndrome (RDS) subjects: selecting appropriate phenotypes for reward dependence behaviors. Int J Environ Res Public Health. 2011;8(12):4425-59.

28. Vallone D, Picetti R, Borrelli E. Structure and function of dopamine receptors. Neurosci Biobehav Rev. 2000;24(1):125-32.

29. Sidhu A, Niznik HB. Coupling of dopamine receptor subtypes to multiple and diverse $\mathrm{G}$ proteins. Int J Dev Neurosci. 2000;18(7):669-77.

30. Volkow ND, Morales M. The Brain on Drugs: From Reward to Addiction. Cell. 2015;162(4):712-25.

31. Johnson PM, Kenny PJ. Dopamine D2 receptors in addiction-like reward dysfunction and compulsive eating in obese rats. Nat Neurosci. 2010;13(5):635-41.

32. McLaren W, Gil L, Hunt SE, Riat HS, Ritchie GR, Thormann A, et al. The Ensembl Variant Effect Predictor. Genome Biol. 2016;17(1):122.

33. Peng S, Du J, Jiang $H$, Fu Y, Chen $H$, Sun $\mathrm{H}$, et al. The dopamine receptor D1 gene is associated with the length of interval between first heroin use and onset of dependence in Chinese Han heroin addicts. J Neural Transm (Vienna). 2013;120(11):1591-8.

34. Novak G, LeBlanc M, Zai C, Shaikh S, Renou J, DeLuca V, et al. Association of polymorphisms in the BDNF, DRD1 and DRD3 genes with tobacco smoking in schizophrenia. Ann Hum Genet. 2010;74(4):291-8.

35. Huo R, Wei Z, Xiong Y, Jiang J, Liu Y, Yan Y, et al. Association of dopamine receptor D1 (DRD1) polymorphisms with risperidone treatment response in Chinese schizophrenia patients. Neurosci Lett. 2015;584:178-83.

36. Carr KA, Lin H, Fletcher KD, Sucheston L, Singh PK, Salis RJ, et al. Two functional serotonin polymorphisms moderate the effect of food reinforcement on BMI. Behav Neurosci. 2013;127(3):387-99.

37. Huang W, Li MD. Differential Allelic Expression of Dopamine D1 Receptor Gene (DRD1) Is Modulated by microRNA miR-504. Biol Psychiatry. 2009;65(8):702-5.
38. Blum K, Oscar-Berman M,

Demetrovics Z, Barh D, Gold MS.

Genetic Addiction Risk Score (GARS):

Molecular Neurogenetic Evidence for

Predisposition to Reward Deficiency

Syndrome (RDS). Mol Neurobiol. 2014;50(3):765-96.

39. Huppertz C, Bartels M, GroenBlokhuis MM, Dolan CV, de Moor MH, Abdellaoui A, et al. The dopaminergic reward system and leisure time exercise behavior: candidate allele study. Biomed Res Int. 2014;2014:591717.

40. Giros B, Sokoloff P, Martres MP, Riou JF, Emorine LJ, Schwartz JC. Alternative splicing directs the expression of two D2 dopamine receptor isoforms. Nature. 1989;342(6252):923-6.

41. White MJ, Morris CP, Lawford BR, Young RM. Behavioral phenotypes of impulsivity related to the ANKK1 gene are independent of an acute stressor. Behav Brain Funct. 2008;4:54.

42. Noble EP, Noble RE, Ritchie T, Syndulko K, Bohlman MC, Noble LA, et al. D2 dopamine receptor gene and obesity. Int J Eat Disord. 1994;15(3):205-17.

43. Obrégon $A M$, Vallandares $M$, Goldfield G. Association of the Dopamine D2 Receptor rs1800497 polymorphism and eating behavior in Chilean children. Nutrition. 2017;35:139-45.

44. Lek FY, Ong HH, Say YH. Association of dopamine receptor $\mathrm{D} 2$ gene (DRD2) Taq1 polymorphisms with eating behaviors and obesity among Chinese and Indian Malaysian university students. Asia Pac J Clin Nutr. 2018;27(3):707-17.

45. Gluskin BS, Mickey BJ. Genetic variation and dopamine D2 receptor availability: a systematic review and meta-analysis of human in vivo molecular imaging studies. Transl Psychiatry. 2016;6(3):e747.

46. Hirvonen MM, Laakso A, Någren K, Rinne JO, Pohjalainen T, Hietala J. C957T polymorphism of dopamine D2 receptor gene affects striatal DRD2 in vivo availability by changing the receptor affinity. Synapse. 2009;63(10):907-12.

47. Davis C, Levitan RD, Yilmaz Z, Kaplan AS, Carter JC, Kennedy JL. Binge eating disorder and the dopamine D2 receptor: genotypes and sub-phenotypes. Prog Neuropsychopharmacol Biol Psychiatry. 2012;38(2):328-35.

48. Kvaløy K, Holmen J, Hveem K, Holmen TL. Genetic effects on longitudinal changes from healthy to adverse weight and metabolic status - The HUNT study. PLoS One. 2015;10(10):e0139632.

49. Dang LC, Samanez-Larkin GR, Castrellon JJ, Perkins SF, Cowan RL, Zald DH. Associations between dopamine D2 receptor availability and BMI depend on age. Neuroimage. 2016;138:176-83.

50. Blum K, Gardner E, Oscar-Berman M, Gold M. "Liking" and "wanting" linked to Reward Deficiency Syndrome (RDS): hypothesizing differential responsivity in brain reward circuitry. Curr Pharm Des. 2012;18(1):113-8.

51. Savitz J, Hodgkinson CA, MartinSoelch C, Shen PH, Szczepanik J, Nugent $A$, et al. The functional DRD3 Ser9Gly polymorphism (rs6280) is pleiotropic, affecting reward as well as movement. PLoS One. 2013;8(1):e54108.

52. Chang TT, Chen SL, Chang YH, Chen PS, Chu $\mathrm{CH}$, Chen $\mathrm{SH}$, et al. The DRD3 Ser9Gly polymorphism predicted metabolic change in drug-naive patients with bipolar II disorder. Medicine (Baltimore). 2016;95(24):e3488.

53. Pouget JG, Shams TA, Tiwari AK, Müller DJ. Pharmacogenetics and outcome with antipsychotic drugs. Dialogues Clin Neurosci. 2014;16(4):555-66.

54. McQuade JA, Benoit SC, Xu M, Woods SC, Seeley RJ. High-fat diet induced adiposity in mice with targeted disruption of the dopamine-3 receptor gene. Behav Brain Res. 2004;151(1-2):313-9.

55. Yazdi FT, Clee SM, Meyre D. Obesity genetics in mouse and human: back and forth, and back again. PeerJ. 2015;3:e856.

56. McGeary J. The DRD4 exon 3 VNTR polymorphism and addiction-related phenotypes: a review. Pharmacol Biochem Behav. 2009;93(3):222-9.

57. Ariza M, Garolera M, Jurado MA, Garcia-Garcia I, Hernan I, SánchezGarre C, et al. Dopamine genes 
(DRD2/ANKK1-TaqA1 and DRD47R) and executive function: their interaction with obesity. PLoS One. 2012;7(7):e41482.

58. Gehricke JG, Swanson JM, Duong S, Nguyen J, Wigal TL, Fallon J, et al. Increased brain activity to unpleasant stimuli in individuals with the 7R allele of the DRD4 gene. Psychiatry Res. 2015;231(1):58-63.

59. Silveira PP, Portella AK, Kennedy JL, Gaudreau H, Davis C, Steiner M, et al. Association between the seven-repeat allele of the dopamine-4 receptor gene (DRD4) and spontaneous food intake in pre-school children. Appetite. 2014;73:15-22.

60. Poston WS 2nd, Ericsson M, Linder J, Haddock CK, Hanis CL, Nilsson T, et al. D4 dopamine receptor gene exon III polymorphism and obesity risk. Eat Weight Disord. 1998;3(2):71-7.
61. Fontana C, Vitolo MR, Campagnolo PD, Mattevi VS, Genro JP, Almeida S. DRD4 and SLC6A3 gene polymorphisms are associated with food intake and nutritional status in children in early stages of development. $J$ Nutr Biochem. 2015;26(12):1607-12.

62. Lowe N, Kirley A, Hawi Z, Sham P, Wickham $\mathrm{H}$, Kratochvil CJ, et al. Joint analysis of the DRD5 marker concludes association with attentiondeficit/hyperactivity disorder confined to the predominantly inattentive and combined subtypes. Am J Hum Genet. 2004;74(2):348-56.

63. Li D, Sham PC, Owen MJ, He L. Metaanalysis shows significant association between dopamine system genes and attention deficit hyperactivity disorder (ADHD). Hum Mol Genet. 2006;15(14):2276-84.

64. Bazar KA, Yun AJ, Lee PY, Daniel SM, Doux JD. Obesity and ADHD may represent different manifestations of a common environmental oversampling syndrome: A model for revealing mechanistic overlap among cognitive, metabolic, and inflammatory disorders. Med Hypotheses. 2006;66(2):263-9.

65. Cornelis $M$, Flint A, Field AE, Kraft P, Han J, Rimm EB, et al. A genome-wide investigation of food addiction. Obesity (Silver Spring). 2016;24(6):1336-41.

66. Borroto-Escuela DO, Van Craenenbroeck K, RomeroFernandez W, Guidolin D, Woods AS, Rivera A, et al. Dopamine D2 and D4 receptor heteromerization and its allosteric receptor-receptor interactions. Biochem Biophys Res Commun. 2011;404(4):928-34.

67. Beeler JA, Faust RP, Turkson S, Ye H, Zhuang X. Low Dopamine D2 Receptor Increases Vulnerability to Obesity Via Reduced Physical Activity, Not Increased Appetitive Motivation. Biol Psychiatry. 2016;79(11):887-97.

Recebido: 29 abr, 2021 Aceito: 7 jun, 2021 